\title{
Transcervical Interstitial Microwave Ablation Therapy for the Treatment of Adenomyosis: A Novel Alternative to Hysterectomy
}

\author{
Yasushi Kanaoka, Hirosumi Imoto \\ Department of Gynecology, Iseikai Hospital, Osaka, Japan \\ Email: kanaokamd@iseikaihp.or.jp
}

Received 25 July 2014; revised 20 August 2014; accepted 16 September 2014

Copyright $@ 2014$ by authors and Scientific Research Publishing Inc.

This work is licensed under the Creative Commons Attribution International License (CC BY). http://creativecommons.org/licenses/by/4.0/

(c) (i) Open Access

\section{Abstract}

Objectives: To investigate the clinical effects of transcervical interstitial microwave irradiation of adenomyotic tissues as an alternative to hysterectomy. Methods: Thirty-three patients who were candidates for hysterectomy for the treatment of adenomyosis associated with menorrhagia were treated by interstitial microwave irradiation using a specifically developed transabdominal ultrasound probe attachment for transcervical puncture along with microwave endometrial ablation, as an alternative to hysterectomy. Primary outcomes were changes in the venous hemoglobin level and the volume of the uterine body before and after treatment. Secondary outcomes were the visual-analogue scale (VAS) score for menorrhagia and dysmenorrhea after treatment. Results: At 3 months after surgery, the average hemoglobin level significantly increased by $4.6 \mathrm{~g} / \mathrm{dL}$. The volume of the uterine body significantly decreased to $53 \%$ and $52 \%$ of the volume before treatment at 3 and 12 months, respectively. VAS scores indicated an improvement in menorrhagia and dysmenorrhea. Conclusions: Transcervical interstitial microwave ablation therapy combined with microwave endometrial ablation reduced the uterine body volume and relieved menorrhagia and dysmenorrheal caused by adenomyosis. This strategy is a promising alternative to hysterectomy for the treatment of symptomatic adenomyosis.

\section{Keywords}

Microwave Ablation, Adenomyosis, Transcervical, Menorrhagia, Dysmenorrhea 


\section{Introduction}

Adenomyosis, most common in women aged 40 - 50 years, is a tumor-like condition defined as the presence of endometrial tissue within the myometrium. It results in an enlarged uterus with thick myometrium and is associated with excessively heavy or prolonged periods and dysmenorrhea. Hysterectomy is presently considered the standard surgical treatment for patients with adenomyosis that is refractory to conservative therapy [1]. However, owing to estrogen dependency, adenomyosis spontaneously degenerates after menopause, and therefore, hysterectomy can be overtreatment for women at perimenopausal ages. A novel, less invasive alternative could replace hysterectomy for such women with adenomyosis.

When the volume of adenomyotic tissue in the uterus is reduced by surgical resection [2] or ablation using some form of physical energy, it is expected that the symptoms caused by adenomyotic tissue would be relieved [3]. Transcervical microwave heating using a transvaginal puncture system has been successfully utilized in ablating symptomatic uterine fibroids [4]; therefore, application of transcervical microwave myolysis to adenomyotic tissue is feasible. To perform transcervical interstitial microwave ablation of adenomyotic tissue under safe and acute ultrasound guidance, we developed a novel transabdominal ultrasound probe attachment specifically designed for transcervical puncture. Using the attachment, we performed transcervical interstitial microwave heating of adenomyotic tissue (transcervical microwave adenomyolysis [TCMAM] combined with microwave endometrial ablation [MEA]) to examine the effects of transcervical microwave ablation therapy for the treatment of adenomyosis.

\section{Patients and Methods}

Between April 2011 and April 2013, 33 consecutive patients presenting with menorrhagia due to diffuse adenomyosis who did not wish to preserve child bearing potential but wanted to avoid hysterectomy were enrolled in this study. 7 patients did not present dysmenorrhea. The study was approved by the Ethics Committee of the Iseikai Hospital, and complete informed consent to the study was provided by every patient prior to participation. Each patient underwent magnetic resonance imaging (MRI) before surgery to confirm the size and location of the adenomyotic lesion in the uterine wall. Patients with intramural or submucosal myomas were excluded. When the distance between the serosa of the uterine fundus and the external orifice of the cervix was more than $15 \mathrm{~cm}, 1.88 \mathrm{mg}$ leuprolerin was subcutaneously administered monthly from 3 months prior to operation, to induce shrinkage of the adenomyotic tissue. The possibility of endometrial malignancy was excluded based on findings of MRI, transvaginal ultrasonography, hysteroscopy, and endometrial biopsy performed before surgery.

Patients underwent TCMAM with MEA in the lithotomy position under general anesthesia using a laryngeal mask. For MEA, a microwave generator Microtaze AZM 550 capable of irradiating microwaves at a frequency of $2.45 \mathrm{GHz}$ and a thin curved microwave applicator (Alfresa Pharma Co., Osaka, Japan) were utilized [5]. After performing MEA under transabdominal ultrasound guidance, a $4 \mathrm{~mm}$ straight microwave applicator with a conic end was transcervically introduced into the uterine cavity using a guiding tube and introduced into the adenomyotic lesion. To maintain the transcervical puncture line within the transabdominal ultrasound imaging plane, a rigid transabdominal ultrasound probe puncture attachment was specifically made of stainless steel, which served as a holder of the guiding tube, also made of stainless steel. A stainless steel needle, $4 \mathrm{~mm}$ in diameter, was specifically developed to pierce the adenomyotic tissue (Figure 1). Before inserting the microwave applicator, the guiding tube, $4.2 \mathrm{~mm}$ in inner diameter, was introduced into the uterine cavity to fix the direction of the puncture line. The stainless steel needle was then inserted into the adenomyotic tissue to create a tunnel for the smooth introduction of the microwave applicator (Figure 2). A straight microwave applicator, $4 \mathrm{~mm}$ in diameter, then replaced the needle. The adenomyotic lesion was continuously irradiated with microwaves at an output of $40 \mathrm{~W}$ in a few irradiation sites for 100 - $650 \mathrm{~s}$ in total, based on its size [4]. Irradiation was continued until the echogenicity of the adenomyotic tissue at the irradiation site increased. During irradiation, the applicator, while its location was fixed, was rotated manually to avoid tissue adhesion on its surface.

The primary outcomes were changes in the blood hemoglobin level and the volume of the uterine body before and after treatment. Hemoglobin was measured before and 3 months after the operation. The size of the uterine body in three directions was measured by MRI or ultrasonography before and 3 and 12 months after the operation. The uterine body was considered to be ellipsoid and its volume was calculated accordingly using the following equation: volume $=(4 / 3) \pi \times(\mathrm{a} / 2) \times(\mathrm{b} / 2) \times(\mathrm{c} / 2)$, where $\mathrm{a}, \mathrm{b}$, and $\mathrm{c}$ represent the length of the uterine 


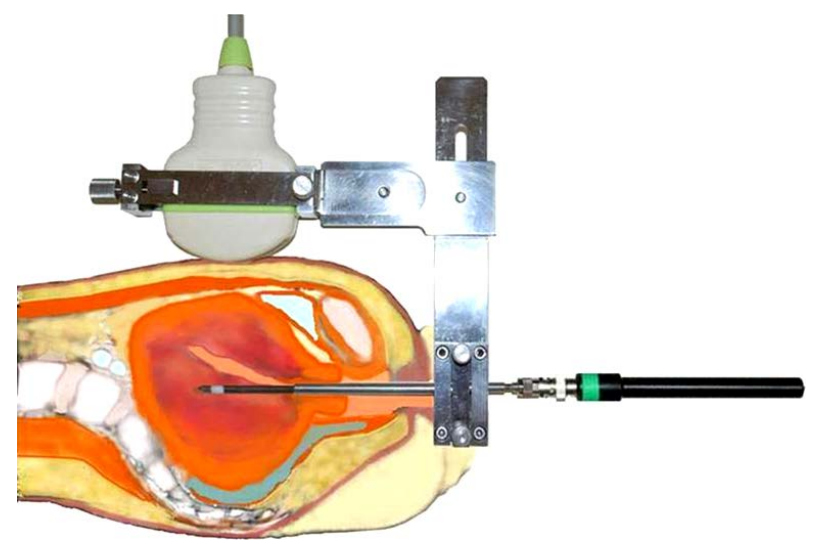

Figure 1. Transcervical microwave adenomyolysis under transabdominal ultrasound guidance.



Figure 2. A specifically designed adaptor for transcervical puncture attached to a transabdominal ultrasound probe.

body measured in three dimensions. The secondary outcomes were changes in the visual-analogue scale (VAS) score for menorrhagia and dysmenorrhea after treatment. Menorrhagia or dysmenorrhea before the operation was assigned a score of 100, whereas the absence of symptoms was assigned a score of 0 . Each patient was interviewed to evaluate VAS scores at 3 and 12 months after the operation.

Statistical analysis was performed using Excel Data Analysis Pack.

\section{Results}

Thirty-three patients underwent TCMAM and MEA. Patient characteristics are summarized in Table 1 . The mean \pm standard deviation of patient age was $45.4 \pm 3.2$ years. The operation time was $48.0 \pm 13.9$ min. Four weeks after TCMAM and MEA, contrast-enhanced MRI revealed a de novo avascular area of $18-27 \mathrm{~mm}$ thickness from the uterine lining in the uterine wall where the adenomyotic tissue was previously located (Figure 3). As shown in Figure 3, the avascular area shrank at 3 months after the operation, with subsequent complete disappearance at 12 months.

The mean \pm standard deviation of the volume of the uterine body was $309 \pm 205 \mathrm{~cm}^{3}$ before the operation, $164 \pm 111 \mathrm{~cm}^{3}$ at 3 months after the operation, and $161 \pm 117 \mathrm{~cm}^{3}$ at 12 months after the operation. A paired t-test indicated that the volume of the uterine body decreased significantly to $53 \%$ and $52 \%$ of the volume before the operation at 3 and 12 months, respectively ( $\mathrm{P}=1.6 \mathrm{E}-6$ and $\mathrm{P}=3.3 \mathrm{E}-5$, respectively). The hemoglobin level significantly increased from a mean \pm standard deviation of $7.9 \pm 2.1 \mathrm{~g} / \mathrm{dL}$ to $12.5 \pm 1.7 \mathrm{~g} / \mathrm{dL}$ at 3 months after the operation ( $\mathrm{P}=2.8 \mathrm{E}-12)$. Subjective improvement in menorrhagia and dysmenorrhea was also observed, as measured by the VAS score, at 3 and 12 months after treatment (Table 1).

Pain after the operation was not severe and could be controlled with non-steroidal anti-inflammatory drugs. 
Table 1. Patients characteristics and clinical results.

\begin{tabular}{|c|c|c|c|}
\hline & Mean & Standard deviation & Range \\
\hline Age (years) & 45.4 & 3.2 & $38-50$ \\
\hline Operation time (min) & 48.0 & 13.9 & $29-88$ \\
\hline \multicolumn{4}{|l|}{ Irradiation time (sec) } \\
\hline MEA & 603 & 145 & $480-1000$ \\
\hline TCMAM & 313 & 152 & $100-650$ \\
\hline \multicolumn{4}{|l|}{ Volume of uterine body $\left(\mathrm{cm}^{3}\right)$} \\
\hline Before operation & $309^{*}$ & 205 & $94-916$ \\
\hline At 3 months $(\mathrm{N}=33)$ & $164^{* a}$ & 111 & $41-700$ \\
\hline At 12 months $(\mathrm{N}=25)$ & $161^{* \mathrm{~b}}$ & 117 & $44-711$ \\
\hline \multicolumn{4}{|l|}{$\mathrm{Hb}(\mathrm{g} / \mathrm{dL})$} \\
\hline Before operation $(\mathrm{N}=33)$ & $7.9^{* *}$ & 2.1 & $2.2-11.8$ \\
\hline At 3 months $(\mathrm{N}=33)$ & $12.5^{* *}$ & 1.7 & $8.4-15.6$ \\
\hline \multicolumn{4}{|l|}{ VAS menorrhagia (\%) } \\
\hline At 3 months $(\mathrm{N}=33)$ & $14.8^{+c}$ & 18.0 & $0-50$ \\
\hline At 12 months $(\mathrm{N}=26)$ & $22.6^{+d}$ & 28.4 & $0-100$ \\
\hline \multicolumn{4}{|l|}{ VAS dysmenorrheal (\%) } \\
\hline At 3 months $(\mathrm{N}=26)$ & $31.3^{+e}$ & 31.8 & $0-100$ \\
\hline At 12 months $(\mathrm{N}=20)$ & $32.1^{+f}$ & 33.5 & $0-80$ \\
\hline
\end{tabular}

${ }^{*} \mathrm{a}: \mathrm{P}=1.6 \mathrm{E}-6$; ${ }^{*} \mathrm{~b}: \mathrm{P}=3.3 \mathrm{E}-5 ;{ }^{* *} \mathrm{P}=2.8 \mathrm{E}-12$ (paired t-test); ${ }^{+} \mathrm{c}: \mathrm{P}=5.88 \mathrm{E}-24 ;{ }^{+} \mathrm{d}: \mathrm{P}=$ $4.2 \mathrm{E}-13{ }^{+} \mathrm{e}$ : $\mathrm{P}=5.4 \mathrm{E}-11{ }^{+}{ }^{+}$: $\mathrm{P}=2.9 \mathrm{E}-8$ (one sample t-test); Hb: hemoglobin; VAS: visualanalogue scale.

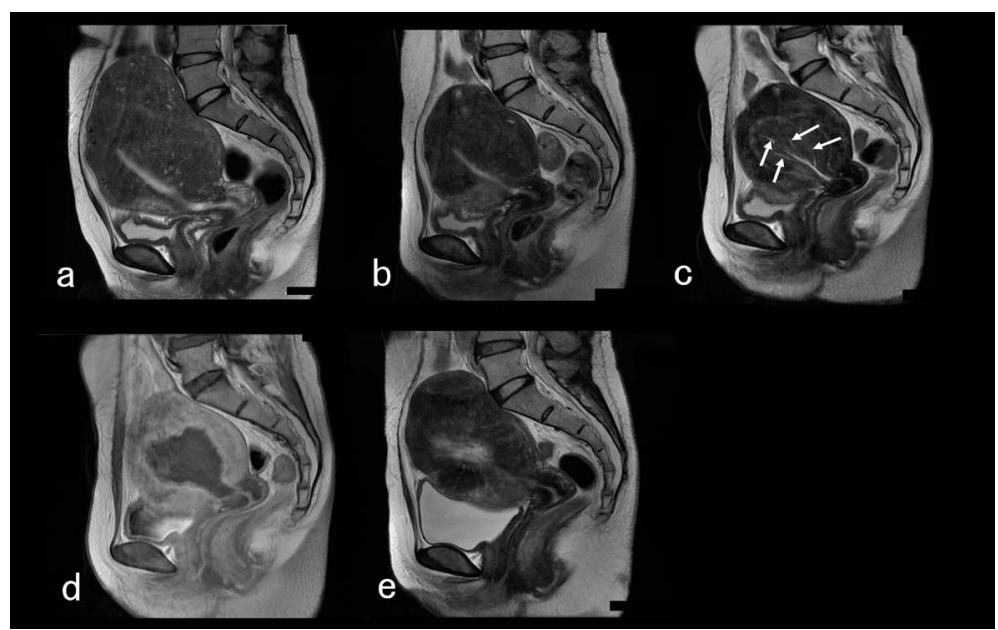

Figure 3. Magnetic resonance images of a 47-year-old patient with adenomyosis. (a) T2-weighted image before gonadotrophin-releasing hormone agonists (GnRHa) treatment; (b) T2-weighted image after 3 months of GnRHa treatment; (c) T2-weighted image 1 month after the operation. White lines (arrows) in the tissue surrounding the uterine cavity are traces of the puncture line; (d) T1-weighted contrast-enhanced image 1 month after the operation. A de novo avascular area was found to replace the adenomyotic lesion. (e) At 12 months after the last administration of leuprolerin, the size of the uterine body was maintained at $52.7 \%$ of that before the operation. Shrinkage of the avascular area and thickening of the uterine wall compared to observations at 1 month are depicted. 
No major complications were encountered during and after the operation, although watery discharge continued for 2 weeks after the operation. One patient experienced a gradual increase in menstrual bleeding without pain and needed tranexamic acid at 16 months, which decreased bleeding until menopause; MRI at 1 month after treatment revealed that the remaining volume of adenomyotic tissue was more than $70 \%$ of that before the operation, and the volume of the uterine body was $80 \%$ of that before the operation. Another patient complained of prolonged serous discharge after the operation. The volume of the patient's uterine body before the operation was $678 \mathrm{~cm}^{3}$, which increased to $700 \mathrm{~cm}^{3}$ at 3 months. Contrast-enhanced MRI at 1 month after treatment revealed that the endometrium and adenomyotic tissue around the uterine cavity was completely necrotized; however, the persistent deep adenomyotic tissue in the posterior wall was more than expected. The serous discharge continued, gradually decreasingly over 24 months, and finally stopped after menopause.

\section{Discussion}

Numerical simulation of the distribution of the electromagnetic field around the microwave applicator in the uterine tissue indicated that microwaves at a frequency of $2.45 \mathrm{GHz}$ cannot efficiently generate heat at more than $5 \mathrm{~mm}$ from the surface of the applicator [5]. In addition, conducting heat through the uterine tissue is swept away by blood perfusion in the neighboring myometrium. Therefore, microwave irradiation of the uterine cavity cannot directly heat deeply situated adenomyotic lesions located apart from the uterine lining. MEA for the treatment of menorrhagia due to adenomyosis is less potent in patients with adenomyotic lesions located deep in the myometrium; deep lesions are not completely necrotized even if the duration or power of microwave irradiation from an applicator tip in the uterine cavity is increased [5]. To overcome the poor penetration of microwaves and cooling due to blood perfusion, TCMAM under transabdominal ultrasound guidance using a specifically developed attachment for transcervical puncture was introduced. The attachment made transabdominal ultrasound-guided puncture and insertion of a microwave applicator very easy. In addition, the tip of the microwave applicator was never lost in the ultrasound imaging plane during microwave irradiation, which made it easy to monitor changes in echogenicity in the irradiated tissue. Owing to the use of the specified puncture system, a transcervical approach was performed smoothly and accurately, and therefore, the main parts of adenomyotic lesions in cases of diffuse adenomyosis were ablated safely. We believe that a transcervical approach to adenomyotic tissue is less invasive than a transvaginal or transabdominal approach [3], because it does not damage any normal tissue other than adenomyotic tissue, endometrium, and neighboring thin myometrium.

TCMAM with MEA significantly decreased the volume of the uterine body enlarged by adenomyosis, and hemoglobin levels increased to the normal range at 3 months, thus, objectively demonstrating the effectiveness of TCMAM with MEA. In addition, the VAS scores indicated menorrhagia and dysmenorrhea improvement.

We believe that TCMAM with MEA has the advantages of short hospital stay and short suspension of social activity. The hospital stay for each patient was within 24 hours, with all patients treated in the afternoon leaving the hospital the next morning. Patients could resume normal social activity within 24 hours, compared with 3 or 4 weeks required for hysterectomy. Furthermore, TCMAM with MEA has the advantages of low surgical cost and short surgical time. The mean total operation time including hysteroscopy before and after microwave ablation was 48 min. The cost of TCMAM with MEA is practically equal to that of MEA alone. Laparoscopic total hysterectomy involves more medical resources and time.

The two patients who avoided hysterectomy with continuing symptoms did not show postoperative shrinkage of the uterine body. These were early cases in this study. The duration of microwave irradiation was likely not sufficient for the volume of adenomyotic tissue. On reviewing all case records, we found that less remaining adenomyotic tissue tended to be associated with fewer symptoms after the operation. We believe that the results improved gradually with experience. The routine use of leuprolerin before the operation is expected to decrease the volume of remaining adenomyotic tissue post-surgery, in addition to shortening the operation time, which will make the replacement of general anesthesia with less expensive anesthesia.

Although a longer observation period is needed to ensure the usefulness of TCMAM with MEA for the treatment of adenomyosis in women in their forties, microwave irradiation may be able to replace hysterectomy at least in perimenopausal women.

\section{Conclusion}

TCMAM with MEA effectively relieved menorrhagia and dysmenorrhea caused by deep adenomyosis. Micro- 
wave ablation induced shrinkage of the uterine body. Low cost, short hospital stay, and ease of surgery are acceptable for both patients and gynecologists. TCMAM with MEA is a promising alternative to hysterectomy for the treatment of adenomyosis.

\section{References}

[1] Levgur, M. (2007) Therapeutic Options for Adenomyosis: A Review. Archives of Gynecology and Obstetrics, 276, 115. http://dx.doi.org/10.1007/s00404-006-0299-8

[2] Grimbizis, G.F., Mikos, T. and Tarlatzis, B. (2014) Uterus-Sparing Operative Treatment for Adenomyosis. Fertility and Sterility, 101, 472-487. http://dx.doi.org/10.1016/j.fertnstert.2013.10.025

[3] Zhang, J., Han, Z.Y., Feng, L., Hu, D.M., et al. (2011) Ultrasound-Guided Percutaneous Microwave Ablation in the Treatment of Diffuse Adenomyosis. Zhonghua Yi Xue Za Zhi, 91, 2749-2752.

[4] Kanaoka, Y., Yoshida, C., Fukuda, T., et al. (2009) Transcervical Microwave Myolysis for Uterine Myomas Assisted by Transvaginal Ultrasonic Guidance. Journal of Obstetrics and Gynaecology Research, 35, 145-151. http://dx.doi.org/10.1111/j.1447-0756.2008.00872.x

[5] Kanaoka, Y., Hirai, H. and Ishiko, O. (2005) Microwave Power and Duration without Extrauterine Thermal Damage in Microwave Endomyometrial Ablation at $2.45 \mathrm{GHz}$. Journal of Obstetrics and Gynaecology Research, 31, 359-367. http://dx.doi.org/10.1111/j.1447-0756.2005.00303.x 
Scientific Research Publishing (SCIRP) is one of the largest Open Access journal publishers. It is currently publishing more than 200 open access, online, peer-reviewed journals covering a wide range of academic disciplines. SCIRP serves the worldwide academic communities and contributes to the progress and application of science with its publication.

Other selected journals from SCIRP are listed as below. Submit your manuscript to us via either submit@scirp.org or Online Submission Portal.
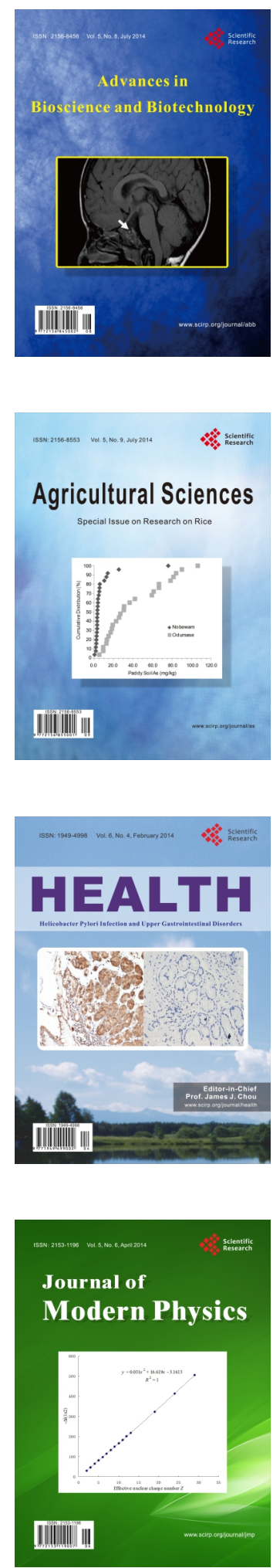
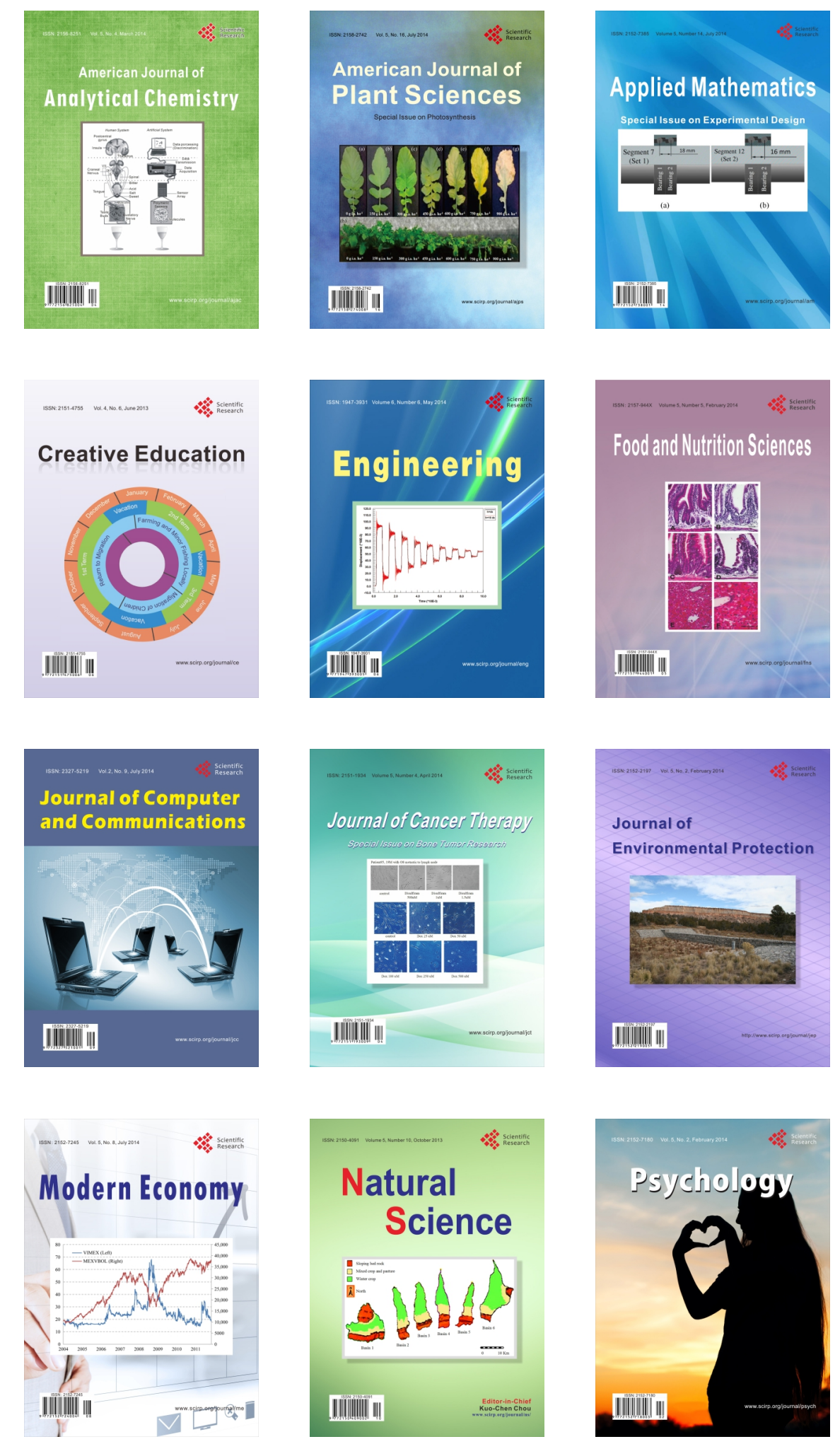